\title{
Kajian Misi Kontekstual Terhadap Spiritualitas Dalam Budaya: Budaya Mabak Sabek Di Dusun Gun Jemak - Kalbar
}

\author{
David Martinus Gulo, ${ }^{1}$ Susilo Susanto, ${ }^{2}$ Joni Manumpak Parulian Gultom ${ }^{3}$ \\ Prodi Teologi, STT Real Batam \\ Prodi Teologi, STT Real Batam \\ Prodi Teologi, STT Real Batam \\ martinusdavidgulo@gmail.com
}

\begin{abstract}
Culture is part of the lives of all individuals, both those who believe in the Lord Jesus or those who do not believe. Likewise with spirituality, every individual must be influenced by their respective cultures. But culture also has values or behavior that are contrary to Bible truth. That is what the writer met when meeting with a Dayak Bidayuh tribe in Gun Jemak. Where the majority of them already believe in Christ but the spirituality of this tribe is strongly influenced by their culture. This is a challenge for missionaries who are on a mission to further study the encounter of the gospel with culture. Therefore by using the ethnographic method the author examines Bidayuh Dayak spirituality that exists in the Mabak Sabek culture with Christian values and how to approach the reconstruction of Christian values that are built upon the appreciation of the culture of Mabak Sabek. With the aim of reviewing contextual missions to improve Christian values in cultural spirituality and reconstruct Christian values to the Dayak community in Gun Jemak with the appreciation of Mabak Sabek's culture.
\end{abstract}

Keywords: Mission, Contextual, Spirituality, Culture

\begin{abstract}
Abstrak
Artikel Budaya bagian dari kehidupan semua individu, baik yang sudah percaya kepada Tuhan Yesus ataupun orang yang belum percaya. Demikian juga dengan spiritualitas, setiap individu pasti dipengaruhi oleh budaya masing-masing. Namun budaya juga memiliki nilai-nilai atau perilaku yang bertentangan dengan kebenaran Alkitab. Demikian yang penulis temui ketika berjumpa dengan satu suku Dayak Bidayuh di Gun Jemak. Dimana mayoritas dari mereka sudah Percaya Kristus tetapi spiritualitas dari suku ini sangat dipengaruhi oleh kebudayaannya. Ini menjadi tantangan bagi misionaris dimana dalam melakukan misi mengkaji lebih jauh antara perjumpaan Injil dengan kebudayaan. Oleh karena itu degan menggunakan metode etnografi penulis mengkaji spiritualitas Dayak Bidayuh yang ada dalam budaya Mabak Sabek dengan nilai-nilai kristiani dan bagaimana cara pendekatan rekonstruksi nilai-nilai kristiani yang di bangun diatas penghayatan budaya Mabak Sabek. Dengan bertujuan mengkaji misi kontekstual guna meningkatkan nilai-nilai Kristiani dalam spiritualitas budaya dan merekontruksi nilai- nialai Kristen kepada masyarakat Dayak di Gun Jemak dengan penghayatan budya Mabak Sabek.

Kata Kunci : Misi, Kontekstual, Spiritualitas, Budaya
\end{abstract}

\section{PENDAHULUAN}

Seluruh masyarakat Dayak Bidayuh yang tinggal di Dusun Gun Jemak sudah menjadi orang percaya. Dalam kehidupan sehari-hari suku ini sangat berhati-hati dalam bekerja dan mematuhi pantangan-pantangan yang ada dalam sistem kebudayaan yang 
dimiliki. Praktek Mabak Sabek dimasa sekarang adalah salah satu bukti bahwa mereka hidup bergantung kepada kuasa Tuhan.

Suku Dayak Bidayuh sangat suka berpesta, mereka dapat mengadakan pesta hingga berhar-hari dengan waktu untuk merayakan telah berlangsungnya ibadah ladang ataupun oleh karena mendapat buruan. Selain tentu saja minum-minum juga termasuk bagian dari kegemaran yang suku Dayak Bidayuh yang berada di pedalaman Gun Jemak. Bahkan minum-minum dapat dikatan sebagai gaya hidup bagi suku ini. Seluruh kegiatan mereka yang bersifat umum, pribadi, bahkan doa ladang tuak menjadi salah satu sajian penting didalam acara yang dilakukan.

Disini misi itu diperlukan, misi gerea tidak cukup hanya sampai Injil itu tersampaikan namun menanamkan nilai-nilai kristiani dalam kehidupan orang percaya juga bagian dari mandat yang diberikan Tuhan Yesus. Sebagaimana dalam Matius 28:20a dituliskan bahwa misi gereja mengajar orang-orang agar memiliki gaya hidup yang berkenan bagi Tuhan.

Suku Dayak Bidayuh sudah belajar berburu dari sejak masa dini. Mereka pergi menjelajahi sungai-sungai untuk menembak ikan. Tentu saja pantangan-pantangan suku ini juga ada saat pergi menangkap ikan. Jadi dari sejak kecil suku sudah memiliki pengetahuan tentang pantangan-pantangan saat beraktifitas didalam hutan ataupun sungai menjadi tempat mereka berburu. Pantanga-pantangan yang begitu banyak dari budaya mereka juga memberi dampak bagi perilaku suku ini. Suku Dayak Bidayuh sangat menghargai orang lain dan suka dengan gotong royong. Mengapa demikian dalam budaya mereka pantang menegur orang yang hendak pergi berbur dan banyak pantangan lainya sehingga sikap yang dimiliki yaitu tidak gemar mengusik kehidupan pribadi orang lain. Namun selain dari sikap mereka yang menghargai orang lain dan suka gotong royong. Kebiasaan berpesta membuat gaya hidup mereka cenderung mabuk mabukan.

Ini menjadi ironi dalam pola gaya hidup sebagai orang percaya. Dimana sebagai orang percaya seharusnya gaya hidupnya menjahui mabuk-mabuk dan pesta pora. Ada dua hal yang dalam spiritualitas Dayak Bidayuh yang dipengarui oleh budaya pertama, gaya hidup yang suka mabuk dan pestapora kedua, motivasi beribadah, dimana jika dilihat dari pola doa Mabak Sabek dan juga pantangan-pantangan lainya yang begitu banyak motivasi yang terbangun yaitu takut akan alam disekitar dan bukan hanya takut akan Allah saja.

Dalam perayaan Mabak Sabek yang sudah dipengaruhi oleh Gereja suku ini pun masih juga mempercayai ramalan. Dalam prakteknya suku ini menyebutnya dengan nenun. Nenun dilakukan untuk menentukan berapa hari lagi lahan akan dibakar. Dalam pekerjaan yang dilakukanpun keadaan-keadaan didalam hutan juga menjadi petunjuk bagi suku itu untuk bertindak salah satu ialah suara burung, ada burung tertentu yang dapat dibedakan oleh suku tersebut jika burung itu berbunyi saat hendak berangkat kemanapun maka suku itu akan mengurung niatnya menunggu hingga burung itu berhenti berbunyi, Sebagian dari mereka ada juga yang berpendapat bahwa itu waktunya untuk berdoa sebelum berangkat. 
Namun, paham yang sesungguhnya bagi suku itu bunyi burung menandakan akan adanya bahaya.

Seperti yang sudah kita dipaparkan diatas dalam Mabak Sabek masih terdapat unsur sinkritisme atau animsme, terlihat saat melakukan doa dengan membacakan mantra untuk meramal cuaca.

Selama enam bulan penulis sudah tinggal bersama - sama dengan masyarakat suku Dayak Bidayuh. Penulis menyaksikan dan pola hidup dan ikut terlibat didalamnya. Masyarakat suku Dayak Bidayuh akan senang mengajak siapa saja yang kebetulan lewat untuk ikut serta dalam pesta yang berlangsung. Selama tinggal disana penulis melihat nilainilai positif yang baik dari suku Dayak Bidayu. Namun, jika ditinjau dari sudah pandang kekristenan pestapora dan mabuk-mabukan bukanlah hal yang positif dan cendrung mengarah kepada dosa. Maka penulis menulis kajian misi kontekstual terhadap budaya ini, dengan harapan dapan menjadi bahan acuan untuk melakukan misi penjangkauan terhadap suku-suku pedalaman.

\section{METODE}

Metode yang digunakan dalam penelitian ini dengan menggunakan metode pengumpulan data atau menggunakan metode penelitian kualitatif karena relative dan kompleks maka data yang dapat terkumpulkan berbentuk kata-kata sehingga tidak terlalu kepada angka.

\section{HASIL DAN PEMBAHASAN}

Menurut Harianto misi merupakan karya dari Allah yang dipercayakan kepadan manusia yaitu memberitakan Injil sampai keujung bumi (Matius 28:19-20). ${ }^{1}$ Gereja memiliki tanggung jawab misi karena gereja telah menerima mandat misi jika kita bandingkan bagaimana misi itu dalam Perjanjian Lama jelas kita dapat menyimpulkan bahwa itu dari Allah dan karya Allah. Dalam nats tersebut jelas sekali bahwa misi gereja adalah pergi menjadikan sebuah bangsa murid Kristus, membabtis dan mengajar mereka untuk melakukan tuga yang Kristus telah ajarkan. Jadi setiap model misi yang dilakukan oleh lembaga gereja merupakan karya dari Allah yang diteruskan kepada manusia.

Widjaja mengatakan bahwa dalam gereja misi adalah mengacu kepada Matius 28:16-20. Yang terkandung didalamnya bukan hanya melakukan penginjilan. Misi gereja menjadikan orang-orang melakukan kehendak Kristus. ${ }^{2}$ Kirk mengatakan bahwa Allah menjadi titik tolak untuk memulai suatu penyelidikan hakikat misi. ${ }^{3}$ Disini kita dapat menyimpulkan bahwa pelaku misi dari berbagai aspek harus bercermin kepada Tuhan. Baik itu pelaku misi ataupun hasil dari misi tersebut yang menjadi titik tolak atau cerimnanya yaitu Allah yang kita kenal dalam pribadi manuisa yaiut Yesus Kristus.

\footnotetext{
${ }^{1}$ Harianto GP, Komunikasi Dalam Pemberitaan Injil (Yogyakarta: ANDI, 2012).131

${ }^{2}$ Fransisku Irwan Widjaja, Misi Dan Pluralitas Keyakinan Indonesia (Yogyakarta: ANDI, 2019).28

${ }^{3}$ J Andrew Kirk, Apa Itu Misi: Suatu Penelusuran Teologis (Jakarta: BPK Gunung Mulia, 2018).27
} 
Gilliland Gultom menjelaskan bahwa terdapat kurang lebih delapan model kontekstualisai. Model-model kontekstualisai tersebut adalah susuatu yang dapat diusahakan. ${ }^{4}$ Kontekstualisai menjadi sarana untuk mempermudah misi. Dengan banyaknya model kontekstualisasi kita dapat menyesuaikan cara kontekstual yang bermanfaat bagi budaya yang ada guna tercapainya tujuan Misi.

\section{Spiritualitas}

Tischler berpendapat bahwa spiritualitas seperti suatu cara, berhubungan dengan emosi atau perilaku dan sikap tertentu dari seorang individu. Menjadi seorang yang spiritual berarti menjadi seorang yang terbuka, memberi, dan penuh kasih. Spiritualitas adalah kebutuhan bawaan manusia untuk berhubungan dengan sesuatu yang lebih besar dari diri manusia itu. Istilah "sesuatu yang lebih besar dari manusia" adalah sesuatu yang diluar diri manusia dan menarik perasaan akan diri orang tersebut. ${ }^{5}$ Calvin dalam Irwanto Pranoto mengatakan Spiritualitas menjelaskan hubungan manusia dengan Tuhan. Spiritualitas dalam terminologi Kristen bila dibandingkan dengan pengertian secara umum tidak terlepas dari keterlibatan Allah dalam penyataan-Nya dan hikmat yang dimiliki manusia. ${ }^{6}$ Pratikto menjelaskan bahwa motivasi spiritual seseorang itu mempengaruhi kinerja, kemampuan mengambik keputusan baik itu dari hasil berpikir, perasaan atau suara hati, pendenganran maupun penglihatan. Dan tingkat spiritualitas seseorang berupaya meniru sifat Allah dalam prilaku hidup. ${ }^{7}$

Demikian juga dengan Mabak Sabek merupakan salah satu bentuk hubungan individu dengan Tuhan. Kata "Mabak Sabek" itu sendiri memiliki makna kata "Mabak" artinya menumpulkan "Sabek" artinya tajam. Disini hubungan individu dengan Tuhan dipengaruhi oleh pemahaman budaya. Suku Bidayuh menganggap bahwa tumbuhan memiliki hak kesetaraan dengan cipataan lainya termasuk manusia. Hal tersebut terlihat jelas dari tujuan mereka melakukan Mabak Sabek tersebut. Suku tersebut memiliki kekhawatiran akan terjadinya hal-hal yang buruk akibat dari menebang pohon sehingga mereka datang dan berdoa memohon perlindungan kepada Tuhan. Sebelum suku tersebut menerima Yesus sebagai Tuhan dan juru selamat doa dari mabak sabek ditujukan kepada dewa atau berhala.

Sekilas kita akan melihat bahwa konsep atau pemahaman budaya ini akan Tuhan sangat baik. Namun jika melihat keseluruhan aktivitas suku tersebut. Banyak hal-hal yang

\footnotetext{
${ }^{4}$ Junifirus Gultom, Teologi Misi Kontekstual (Jakarta: BPK Gunung Mulia, 2018). 158-159

${ }^{5}$ Len Tischler, Jerry Biberman, and Robert Mckeage, "Linking Emotional Intelligence, Spirituality and Workplace Performance:Definitions, Models and Ideas for Research," Journal of Managerial Psychology 17, no. 3 (2002): 203-218.

${ }^{6}$ Irwanto Pranoto, "Relevansi Konsep, Spiritualitas Calvin Dalam Konteks Masa Kini,” Jurnal Veritas 6, no. 1 (2005).63

${ }^{7}$ Heri Pratikto, "Motivasi Spiritual Dan Budaya Sekolah Berpengaruh Terhadap Kinerja Profesional Dan Perilaku Konsumsi Guru Ekonomi," JURNAL PENDIDIKAN DAN PEMBELAJARAN 19, no. 1 (2012): 125137.132
} 
bertentangan dengan Alkitab, suku tersebut cenderung lebih percaya kepada ilah-ilah atau takhayul yang turun temurun sudah diajarkan dalam budaya mereka, sehingga spiritualias yang ada lebih memiliki penghormatan atas budaya dibanding dengan nilai-nilai kebenaran dalam Alkitab. Hal itu terjadi dikarenakan pemahaman yang didapat dari Budaya adalah takut akan alam dan sekitar, dimana kita sebagai orang percaya harus memiliki sifat takut akan Tuhan bukan alam dan linggkungan. Budaya ini merupakan ritual doa yang dilakukan oleh suku Dayak Bidayuh sebelum pembakaran lahan. Tidak hanya Dayak Bidayuh semua masyarakat Dayak di pedalaman Kalimantan Barat melakukan ritual yang sama namun dengans sebutan yang berbeda-beda.

\section{MISI KONTEKSTUAL BERSUMBER DARI ALLAH}

Misi Kontekstual adalah cara untuk mencapai sebuah tujuan yang disesuaikan dengan konteks yang ada. Kontekstual juga sesuatu yang Allah lakukan juga dalam pernyataannya. kita dapat menemukan dalam Alkitab bahwa Allah juga bersifat kontekstual dalam pernyataan Dirinya. Maka dengan melakukan kontekstual terhadap budaya dengan tujuan menyatakan Allah dan Yesus Kristus sebagai Juruselamat. Kita dapat menemukan dalam Alkitab bahwa Allah juga bersifat kontekstual dalam pernyataan Dirinya. Dalam Kejadian 12:1-9 ketika Allah memanggil Abraham. Dalam Yosusa 24:1 dijelaskan bahwa Abraham berasal dari keluarga yang menyembah allah lain. Ketika Allah berbicara kepada Abraham dalam Kejadian 12:6-7, Allah berjumpa dengan Abraham menggunakan konsep penyembahan yang dilakukan oleh konsep yang dipahami oleh Abraham. Sebagaimana dalam Yosua: 24:2 dikatakan bahwa Terah, ayah Abraham dan ayah Nahor, dan mereka beribadah kepada allah lain. Artinya konsep beribadah yang dipahami oleh Abraham adalah konsep yang diajarkan dalam keluarganya. Dapat disimpulkan bahwa dengan kontekstual kita dapat berjumpa dengan Allah namun kita dapat melihat bagaimana sipiritualitas Abraham yang semakin bertumbuh dan berbeda dari orang yang ada disekitarnya. Hal ini tidak dipengaruhi oleh konsep beribadahnya tetapi karena pengenalan Abraham akan Allah yang semakin baik dalam perjalanannya hidupnya. Konsep yang di pakai Abraham boleh sama dengan orang sekitarnya atau keluarganya, tetapi karena perbedaan pengenalan Akan Allah dan Allah yang di sembah oleh Abraham berebeda sehingga menghasilkan spiritualitas yang berbeda pula.

Kita dapat melihat dalam Perjanjian Lama tugas misi dari sudut panggilan dan pengutusan Israel. ${ }^{8}$ Dalam Perjanjian Lama Kejadian 12:2-3 kita dapat melihat maksud dari misi Allah terhadap bangsa Israel. Janji Allah kepada Abraham menjadikannya bangsa yang besar sebagaimana kita mengetahui penggenapan akan janji Allah itu adalah bangsa Israel. Namun dari janji Allah kita dapat melihat misi Allah itu. Allah menghendaki setiap bangsa yang ada disekitarnya mengalami berkat dari Allah atau Allah mengehendaki

\footnotetext{
${ }^{8}$ Fransiskus Irwan Widjaja, Misiologi Antara Teori, Fakta Dan Pengalaman, 1st ed. (Batam: Andi Offset Yogyakarta, 2018).1
} 
bangsa-bangsa disekitar Israel dapat mengenal-Nya degan melihat kepada Israel. Allah terhadap bangsa disekitar Israel dapat rujuk kepada sikap Allah terhadap bangsa Niniwe sebagai contoh. Allah mengutus Yunus untuk melakukan misi untuk menyampaikan pesan Allah. Dalam Kitab Yunus 1-4 kita dapa melihat sikap keperdulian Allah kepada bangsa disekitar Israel. Allah menghendaki Yunus untuk melakukan misi dengan harapan terjadi pertobatan dari bangsa itu. Dalam Wijaja dijelaskan bahwa Allah menaruh perhatiannya kepada bangsa-bangsa lain sebagai contoh bangsa Niniwe itu merupakan bentuk perhatian dan kemurahan Allah dan keinginan Allah agar bangsa-bangsa lain menerima berkat dari Allah. ${ }^{9}$

\section{KONTEKSTUALISASI DALAM SUKU BIDAYUH}

Dalam prakteknya kita dapat melihat bahwa kontekstualiasasi terjadi dalam budaya tersebut dengan model adaptasi. Menurut Gultom kontekstualisasi adaptasi adalah membuat sedapat mungkin sejarah dari teoglogi sistematis cocok dengan situasi-situasi budaya tertentu. ${ }^{10}$ Jika kita pratekan terhadap pendekataN budaya Mabak Sabek. Maka metode dari misi kontektstual ini berusaha mempengaruhi budaya dengan filosofi-filosofi yang ada diadaptasikan dengan tema-tema yang muncul dari budaya. Kita dapat lihat dari praktek doa Mabak Sabek ataupun budaya ladang selain dari Mabak Sabek. Ritual doa untuk ladang sudah ada dari sebelum Injil masuk kedalam wilayah pedalaman Kalimantan Barat. Setelah mereka menerima Injil atau menerima Yesus sebagai Tuhan dan Juruselamat. Penyembahan yang tadinya di tujukan kepada berhala sekarang ditujukan kepada Tuhan Yesus, dan syarat-syarat lama yang dituntut harus disediakan kini tidak lagi menjadi suatu keharusan sehingga untuk melakukannya lebih muda, walaupun masih ada juga konsep yang diikuti dari sarat-sarat sebelum mengenal Kristus. Namun tetap model praktek dari Mabak Sabek mengacu kepada ritual yang sesungguhnya.

Sehingga budaya ini mempengaruhi spiritualitas dari suku tersebut. Budaya ini menjadikan masyaraktanya menjadi orang yang suka mabuk mabukan. Karena dalam perayaan acara Mabak Sabek, tuak menjadi salah satu syarat yang penting yang harus disediakan. Penulis membaca naskah yang sudah dipatenkan oleh gereja yang ada di daerah suku tersebut. Organisasi gereja yang ada merumuskan atau menyusun sebuah rangkaian proses acara yang dilakukan untuk Mabak Sabek dan didalam buku panduan ibdah ladang tersebut penulis menemukan syarat yang harus disediakan untuk doal ladang salah satunya adalah tuak. Budaya meminum tuak dikalangan suku tersebut bukan karena adanya aturan yang telah disusun oleh gereja melainkan buku tersebut disusun berdasarkan budaya yang ada.

\footnotetext{
${ }^{9}$ Hengki Wijaya, "Misiologi Berdasarkan Perjanjian Lama Dan Perjanjian Baru," Journal Jaffray (2013).22

${ }^{10}$ Gultom, Teologi Misi Kontekstual.36
} 
Jika melihat kenyataan yang terjadi, maka tidak heran jika spiritualitas dari suku tersebut lebih dipengaruhi oleh budaya dibandingkan oleh ajaran Firman itu sendiri. Riniwati menjelaskan bahwa orang yang menyatakan bahwa ia beriman pada Allah, harus membuktikan imannya itu di dalam kehidupannya. ${ }^{11}$ Kontektual Misi yang sudah berlangung masih hanya menggantikan arah fokus kepercayaannya yang ada yang sebelumnya tertuju kepada berhala menjadi tertuju kepada Tuhan Yesus. Namun nilai-nilai kristiani tidak bertumbuh didalamnya. Bagi suku ini nilai adat atau budaya berada diatas segalanya. Hal ini terjadi karena kurangnya pemahaman akan Firman. Bagi suku ini lebih penting melakukan kegiatan yang berkaitan dengan budaya dibanding dengankan dengan kegiatan-kegiatan kerohanian di gereja.

Dalam misi orang Kristen seharusnya menjadi orang yang memberitakan Injil atau dapat juga kita sebut dengan sebutan komunikator Kristen. Namun seorang penginjil tidak hanya menceritakan Yesus kepada seseorang. Namun pemberita Injil juga mengajarkan polah hidup. ${ }^{12}$ Maka gerja perlu merekontruksi nilai-nilai kristiani dalam pola hidup suku Dayak di Gun Jemak maka misi tersebut dapat dilakukan dengan pendekatan model kontekstual kounter budaya dengan di kombinasikan dengan model adaptasi. Pelaku misi tidak menolak budaya masyarakat di Gun Jemak namun terlibat menjadi pelaku dari budaya tersebut. Namun dalam prosesnya pelaku misi secara perlahan memberikan contoh praktek yang sesuai kehendak Kristus. Dalam Gultom dijelaskan model kounter budaya menganggap konteks sebagai suatu penghalang bagi Injil dan pesan Injil. Teologi kontekstual pada model ini dilakukan bukan sebagai suatu penerjemah Injil kepada konteks, bukan pula untuk mengizinkan konteks untuk meyediakan prespektif baru atau agenda bagi refleksi teologis, tetapi sebagi suatu perjumpaan atau keterlibatan dengan budaya. $^{13}$

Dengan demikan nilai-nilai kristiani yang tertupi oleh pengaruh budaya dalam direkonstruksi karena dalam misi gereja budaya tidak ditaruh di posisi paling atas. Maka penting sekali gereja untuk menghimbau atau mengajak jemaat supaya rajin membaca Alkitab. Dengan demikan maka nilai-nila kebenar Firman akan dapat deketahui. Suku tersebut lebih menaati pantangan adat dibandingkan nilai-nilai kristiani bukan hanya karena budaya itu saja tetapi disebabkan lemahnya pengetahuan akan Firman. Hampir seluruh anak-anak yang ada wilayah Gun Jemak tidak mengenal satupun tokoh-tokoh Alkitab selain daripada Yesus Kristus dan Maria, artinya mereka tidak mengetahui apa saja yang terjadi atau tertulis dalam Alkitab. Mengenal tokoh-tokoh dalam Alkitab sejak dini itu sangat penting, dengan begitu dari sejak dini nilai-nilai kebenaran sudah ditanamkan.

Adapun model kounter budaya ini dipakai tetap harus di kombinasikan dengan model adaptasi. Dimana sebagai pelaku misi terhadap suku tersebut kita harus menjadi

\footnotetext{
${ }^{11}$ Riniwati, "Iman Kristen Dalam Pergaulan Lintas Agama,” Jurnal Simpson 1, no. 1 (2014): 21-36.23

${ }^{12}$ GP, Komunikasi Dalam Pemberitaan Injil.137

${ }^{13}$ Gultom, Teologi Misi Kontekstual.160
} 
sama dengan mereka. Menjadi masyarakat atau penduduk di dusun Gun Jemak adalah cara yang paling mudah untuk mejadi teladan bagi penduduk disana. Dengan demikian pelaku misi dapat memiliki ladang sendiri dan dapat melakukan praktek budaya ladang dengan spiritualitas Kristen.

\section{KESIMPULAN}

Budaya Masyarakat Dayak Bidayu sangat berpengaruh pada spiritualitas penduduk di Gun Jemak. Motivasi penduduk Gun Jemak dalam melakukan budaya Mabak Sabek tidak murni tertuju kepada hubungan kepada Tuhan. Misi Gereja tidak hanya memberitakan Injil, tetapi mengajar dan memperlengkapi orang percaya juga bagian dari misi Gereja. oleh karena itu Gereja perlu melakukan misi untuk merekntruksi nilai-nilai kristiani dalam pola hidup masyarakat di Gun Jemak.

\section{KEPUSTAKAAN}

GP, Harianto. Komunikasi Dalam Pemberitaan Injil. Yogyakarta: ANDI, 2012.

Gultom, Junifirus. Teologi Misi Kontekstual. Jakarta: BPK Gunung Mulia, 2018.

Kirk, J Andrew. Apa Itu Misi: Suatu Penelusuran Teologis. Jakarta: BPK Gunung Mulia, 2018.

Pranoto, Irwanto. "Relevansi Konsep, Spiritualitas Calvin Dalam Konteks Masa Kini." Jurnal Veritas 6, no. 1 (2005).

Pratikto, Heri. "Motivasi Spiritual Dan Budaya Sekolah Berpengaruh Terhadap Kinerja Profesional Dan Perilaku Konsumsi Guru Ekonomi." JURNAL PENDIDIKAN DAN PEMBELAJARAN 19, no. 1 (2012): 125-137.

Riniwati. "Iman Kristen Dalam Pergaulan Lintas Agama." Jurnal Simpson 1, no. 1 (2014): 21-36.

Tischler, Len, Jerry Biberman, and Robert Mckeage. "Linking Emotional Intelligence, Spirituality and Workplace Performance:Definitions, Models and Ideas for Research." Journal of Managerial Psychology 17, no. 3 (2002): 203-218.

Widjaja, Fransisku Irwan. Misi Dan Pluralitas Keyakinan Indonesia. Yogyakarta: ANDI, 2019.

Widjaja, Fransiskus Irwan. Misiologi Antara Teori, Fakta Dan Pengalaman. 1st ed. Batam: Andi Offset Yogyakarta, 2018.

Wijaya, Hengki. "Misiologi Berdasarkan Perjanjian Lama Dan Perjanjian Baru." Journal Jaffray (2013). 